\title{
On common $\alpha$-fuzzy fixed points with applications
}

\author{
Abdul Latif ${ }^{1}$, Antonio-Francisco Roldán-López-de-Hierro² and Wutiphol Sintunaravat ${ }^{3 *}$
}

"Correspondence:

wutiphol@mathstat.sci.tu.ac.th; poom_teun@hotmail.com

${ }^{3}$ Department of Mathematics and

Statistics, Faculty of Science and Technology, Thammasat University,

Rangsit Center, Pathumthani, 12121, Thailand

Full list of author information is available at the end of the article

\begin{abstract}
In this paper, we introduce a notion of $\alpha$-continuity of fuzzy mappings and some generalized contractive conditions for $\alpha$-level sets. Then we prove some theorems on the existence of common $\alpha$-fuzzy fixed points for a pair of fuzzy mappings. Consequently, we obtain some results on metric spaces endowed with binary relations, and graphs. Further, using $\alpha$-fuzzy fixed point techniques we obtain common fixed point results for multi-valued mappings on metric spaces.
\end{abstract}

Keywords: $\alpha$-continuous fuzzy mappings; $\alpha$-fuzzy fixed point; fuzzy mapping; fuzzy set; fuzzy topology

\section{Introduction}

In 1965, Zadeh firstly introduced and studied the notion of fuzzy set in his seminal paper [1], which opened an avenue for further development of analysis in this field. Afterward, it was developed extensively by many researchers, which also included many interesting applications of this theory in different fields such as neural network theory, stability theory, mathematical programming, modeling theory, engineering sciences, medical sciences (medical genetics, nervous systems), image processing, control theory, communication, etc. In 1981, Heilpern [2] proved the fuzzy Banach contraction principle for fuzzy contractive mappings on a complete linear metric space provided with $d_{\infty}$-metric for fuzzy sets. This result is an improvement and a generalization of the well known Nadler contraction principle [3]. Further, Frigon and O'Regan [4] extended Heilpern's result under a contractive condition for 1-level sets of a fuzzy contraction on a complete metric space, where 1-level sets are not assumed to be convex and compact. In 2009, Azam and Beg [5] proved existence theorems of common fixed points for a pair of fuzzy mappings under Edelstein, Alber and Guerr-Delabriere's type contractive conditions in a linear metric space. Later, Azam et al. [6] showed existence theorems of fixed points for fuzzy mappings satisfying Edelstein locally contractive conditions on a compact metric space provided with the $d_{\infty}$-metric for fuzzy sets. Besides, there are many results about fixed points of fuzzy mappings with different contractive contractions.

In 2013, Azam and Beg [7] established a common $\alpha$-fuzzy fixed point result for a pair of fuzzy mappings on a complete metric space under a generalized contractivity condition for $\alpha$-level sets via Hausdorff metrics for fuzzy sets, which generalized the results proved by Azam and Arshad [8], Bose and Sahani [9] and Vijayaraju and Marudai [10], among others. Recently, Phiangsungnoen et al. [11] extended the Azam and Beg's main results [7] by using

\section{Springer}

C2014 Latif et al.: licensee Springer. This is an Open Access article distributed under the terms of the Creative Commons Attribution License (http://creativecommons.org/licenses/by/2.0), which permits unrestricted use, distribution, and reproduction in any medium, provided the original work is properly cited. 
the concept of $\beta_{\mathcal{F}}$-admissible pairs which is a generalization of the notion of $\beta$-admissible pairs for multi-valued mappings due to Mohammadi et al. [12]. For the supremum metric spaces and fixed points of fuzzy mappings, see also [13-16]. Other notions of fixed point in the fuzzy ambient can be found in $[17,18]$ (see also $[1,10,15,16,19-31]$ ).

In this work, we introduce the notion of $\alpha$-continuity of fuzzy mappings and we present some generalized contractive conditions for $\alpha$-level sets via Hausdorff metrics for fuzzy sets. We establish common $\alpha$-fuzzy fixed point theorems under such conditions and we also show some consequences of our results on metric spaces endowed with an arbitrary binary relation and on metric spaces endowed with graphs. Finally, we use $\alpha$-fuzzy fixed point techniques to deduce common fixed point results for multi-valued mappings. Our results improve, extend, and generalize many results existing in the literature.

\section{Preliminaries}

Throughout this paper, we denote by $X$ a nonempty set and $2^{X}$ stands for the collection of all nonempty subsets of $X$. A fuzzy set on $X$ is a function $\mathcal{A}$ with domain $X$ and values in $[0,1]$. If $\mathcal{A}$ is a fuzzy set and $x \in X$, then the function-value $\mathcal{A}(x)$ is called the grade of membership of $x$ in $\mathcal{A}$. Given $\alpha \in(0,1]$, the $\alpha$-level set of $\mathcal{A}$ is the set $[\mathcal{A}]_{\alpha}=\{x \in X: \mathcal{A}(x) \geq \alpha\}$. If $X$ is endowed with a topology, then the 0 -level set of $\mathcal{A}$ is $[\mathcal{A}]_{0}=\overline{\{x \in X: \mathcal{A}(x)>0\}}$, where $\bar{B}$ denotes the closure of $B \subseteq X$.

In the sequel, assume that $(X, d)$ is a metric space. For a point $x$ in $X$ and a nonempty subset $A \subseteq X$, the distance $d(x, A)$ from $x$ to $A$ is

$$
d(x, A)=\inf \{d(x, a): a \in A\} .
$$

It is clear that $d(x, A)=d(x, \bar{A}) \geq 0$, and $d(x, A)=0$ if, and only if, $x \in \bar{A}$.

Let $\mathcal{F}(X)$ denote the collection of all fuzzy sets in $X$ (provided with the metric topology) and let $\mathrm{CB}(X)$ be the family of nonempty closed bounded subsets of $(X, d)$. We denote by $\{x\}$ the fuzzy set $\chi_{\{x\}}$, where $\chi_{A}$ is the characteristic function of the crisp set $A \in 2^{X}$. Notice that there exists an injective mapping $\chi: 2^{X} \rightarrow \mathcal{F}(X)$ that associates $\chi_{A} \in \mathcal{F}(X)$ to each $A \in 2^{X}$, and that lets us see $\mathrm{CB}(X)$ as a subset of $\mathcal{F}(X)$.

For $A, B \in \mathrm{CB}(X)$, we define the Hausdorff distance between $A$ and $B$ by

$$
H(A, B)=\max \left\{\sup _{a \in A} d(a, B), \sup _{b \in B} d(b, A)\right\}
$$

which is symmetric in $A$ and $B$. It is well known that $(\mathrm{CB}(X), H)$ is a metric space.

Definition 1 Let $X$ be a nonempty set and $Y$ be a metric space. A mapping $T$ is said to be a fuzzy mapping if $T$ is a mapping from $X$ into $\mathcal{F}(Y)$.

Remark 2 The function-value $(T x)(y)$ is the grade of membership of $y$ in $T x$.

Definition 3 Let $(X, d)$ be a metric space, let $\alpha \in[0,1]$ and let $S$ and $T$ be fuzzy mappings from $X$ into $\mathcal{F}(X)$. A point $z$ in $X$ is called an $\alpha$-fuzzy fixed point of $T$ if $z \in[T z]_{\alpha}$. The point $z$ is called a common $\alpha$-fuzzy fixed point of $S$ and $T$ if $z \in[S z]_{\alpha} \cap[T z]_{\alpha}$. When $\alpha=1$, it is called a common fixed point of $S$ and $T$. 
Remark 4 Notice that the notion of common $\alpha$-fuzzy fixed point of $S$ and $T$ depends on the level sets $[S z]_{\alpha}$ and $[T z]_{\alpha}$. In this sense, it would be more appropriate to call it a common $\alpha$-level set-valued fuzzy fixed point of $S$ and $T$. However, in order not to complicate the notation, we follow the original notation introduced in [11].

Lemma 5 Let $(X, d)$ be a metric space and $A, B \in \mathrm{CB}(X)$, then for each $a \in A$ and all $b \in B$

$$
d(a, B) \leq H(A, B) \quad \text { and } \quad d(a, B) \leq d(a, b) .
$$

Proposition 6 If $\left\{x_{n}\right\} \rightarrow x$ in a metric space $(X, d)$ and $\emptyset \neq A \subseteq X$, then $\left\{d\left(x_{n}, A\right)\right\} \rightarrow$ $d(x, A)$.

Proof It follows from the fact that, for all $a \in A$ and $n \in \mathbb{N}, d(x, a) \leq d\left(x, x_{n}\right)+d\left(x_{n}, a\right) \leq$ $2 d\left(x, x_{n}\right)+d(x, a)$. Taking the infimum on $a \in A$, it follows that $d(x, A) \leq d\left(x, x_{n}\right)+d\left(x_{n}\right.$, $A) \leq 2 d\left(x, x_{n}\right)+d(x, A)$ for all $n \in \mathbb{N}$. Now, letting $n \rightarrow \infty$, we conclude that $\left\{d\left(x_{n}, A\right)\right\} \rightarrow$ $d(x, A)$.

Lemma 7 (Nadler [3]) Let $(X, d)$ be a metric space and $A, B \in \mathrm{CB}(X)$, then for each $a \in A$, $\varepsilon>0$, there exists an element $b \in B$ such that

$$
d(a, b) \leq H(A, B)+\varepsilon .
$$

Definition 8 ([19]) Let $X$ be a nonempty set and let $T: X \rightarrow X$ and $\beta: X \times X \rightarrow[0, \infty)$ be two mappings. We say that $T$ is $\beta$-admissible if

$$
x, y \in X, \quad \beta(x, y) \geq 1 \quad \Rightarrow \quad \beta(T x, T y) \geq 1 .
$$

Definition 9 ([32]) Let $X$ be a nonempty set and let $T: X \rightarrow 2^{X}$ and $\beta: X \times X \rightarrow[0, \infty)$ be two mappings. We say that $T$ is $\beta_{*}$-admissible if

$$
x, y \in X, \quad \beta(x, y) \geq 1 \quad \Rightarrow \quad \beta_{*}(T x, T y) \geq 1,
$$

where

$$
\beta_{*}(A, B)=\inf \{\beta(a, b): a \in A, b \in B\} .
$$

Definition 10 ([12]) Let $X$ be a nonempty set and let $T: X \rightarrow 2^{X}$ and $\beta: X \times X \rightarrow[0, \infty)$ be two mappings. We say that $T$ is $\beta$-admissible whenever for each $x \in X$ and $y \in T x$ with $\beta(x, y) \geq 1$, we have $\beta(y, z) \geq 1$ for all $z \in T y$.

Definition 11 ([11]) Let $(X, d)$ be a metric space and let $\alpha: X \rightarrow(0,1], \beta: X \times X \rightarrow[0, \infty)$ and $S, T: X \rightarrow \mathcal{F}(X)$ be four mappings. The ordered pair $(S, T)$ is said to be $\beta_{\mathcal{F}}$-admissible if it satisfies the following conditions:

(i) for each $x \in X$ and $y \in[S x]_{\alpha(x)}$, with $\beta(x, y) \geq 1$, we have $\beta(y, z) \geq 1$ for all $z \in[T y]_{\alpha(y)}$;

(ii) for each $x \in X$ and $y \in[T x]_{\alpha(x)}$, with $\beta(x, y) \geq 1$, we have $\beta(y, z) \geq 1$ for all $z \in[S y]_{\alpha(y)}$. If $S=T$ then $T$ is called $\beta_{\mathcal{F}}$-admissible. 
It is easy to see that if $(S, T)$ is $\beta_{\mathcal{F}}$-admissible, then $(T, S)$ is also $\beta_{\mathcal{F}}$-admissible.

Definition $12([11])$ Let $(X, d)$ be a metric space, $\beta: X \times X \rightarrow[0, \infty)$ and $F, G: X \rightarrow$ $\mathrm{CB}(X)$. The ordered pair $(F, G)$ is said to be $\beta$-admissible if it satisfies the following conditions:

(i) for each $x \in X, y \in F x$ with $\beta(x, y) \geq 1$, we have $\beta(y, z) \geq 1$ for all $z \in G y$;

(ii) for each $x \in X, y \in G x$ with $\beta(x, y) \geq 1$, we have $\beta(y, z) \geq 1$ for all $z \in F y$.

Remark 13 It is easy to prove that $(F, G)$ is $\beta$-admissible if, and only if, $(G, F)$ is $\beta$-admissible. If $F=G$, then $G$ is called $\beta$-admissible (this notion was introduced by Mohammadi et al. in [12]).

We will use the following property.

Lemma 14 Let $\left\{x_{n}\right\}$ be a sequence in a metric space $(X, d)$ and assume that there exists $\lambda \in[0,1)$ such that

$$
d\left(x_{n+1}, x_{n+2}\right) \leq \lambda d\left(x_{n}, x_{n+1}\right)+\lambda^{n} \text { for all } n \geq 0 \text {. }
$$

Then $\left\{x_{n}\right\}$ is a Cauchy sequence.

Proof By induction, it follows from (2) that

$$
d\left(x_{n}, x_{n+1}\right) \leq \lambda^{n} d\left(x_{0}, x_{1}\right)+n \lambda^{n-1} \quad \text { for all } n \geq 1
$$

Therefore, if $n, m \in \mathbb{N}$ verify $n<m$, then

$$
\begin{aligned}
d\left(x_{n}, x_{m}\right) \leq & d\left(x_{n}, x_{n+1}\right)+d\left(x_{n+1}, x_{n+2}\right)+\cdots+d\left(x_{m-2}, x_{m-1}\right)+d\left(x_{m-1}, x_{m}\right) \\
\leq & \left(\lambda^{n} d\left(x_{0}, x_{1}\right)+n \lambda^{n-1}\right)+\left(\lambda^{n+1} d\left(x_{0}, x_{1}\right)+(n+1) \lambda^{n}\right)+\cdots \\
& +\left(\lambda^{m-2} d\left(x_{0}, x_{1}\right)+(m-2) \lambda^{m-3}\right) \\
& +\left(\lambda^{m-1} d\left(x_{0}, x_{1}\right)+(m-1) \lambda^{m-2}\right) \\
= & d\left(x_{0}, x_{1}\right) \sum_{k=n}^{m-1} \lambda^{k}+\sum_{k=n}^{m-1} k \lambda^{k-1} .
\end{aligned}
$$

d'Alembert's ratio test for series of real numbers guarantees that the series $\sum_{k \geq 1} \lambda^{k}$ and $\sum_{k \geq 1} k \lambda^{k-1}$ are convergent. As a consequence, $\lim _{n, m \rightarrow \infty} d\left(x_{n}, x_{m}\right)=0$ and $\left\{x_{n}\right\}$ is a Cauchy sequence.

\section{Common $\alpha$-fuzzy fixed point theorems}

In [11], Phiangsungnoen et al. proved the following theorem.

Theorem 15 ([11]) Let $(X, d)$ be a complete metric space and let $S, T: X \rightarrow \mathcal{F}(X), \alpha: X \rightarrow$ $(0,1]$ and $\beta: X \times X \rightarrow[0, \infty)$ be four mappings such that the following properties are fulfilled.

(a) For all $x, y \in X$, we have $[S x]_{\alpha(x)},[T y]_{\alpha(y)} \in \mathrm{CB}(X)$. 
(b) There exist $a_{1}, a_{2}, a_{3}, a_{4}, a_{5} \in[0,1)$ such that $a_{1}+a_{2}+a_{3}+a_{4}+a_{5}<1$ and either $a_{1}=a_{2}$ or $a_{3}=a_{4}$, verifying

$$
\begin{aligned}
\max \{ & \beta(x, y), \beta(y, x)\} H\left([S x]_{\alpha(x)},[T y]_{\alpha(y)}\right) \\
\leq & a_{1} d\left(x,[S x]_{\alpha(x)}\right)+a_{2} d\left(y,[T y]_{\alpha(y)}\right)+a_{3} d\left(x,[T y]_{\alpha(y)}\right) \\
& +a_{4} d\left(y,[S x]_{\alpha(x)}\right)+a_{5} d(x, y)
\end{aligned}
$$

for all $x, y \in X$.

(c) $(S, T)$ is a $\beta_{\mathcal{F}}$-admissible pair.

(d) There exist $x_{0} \in X$ and $x_{1} \in\left[S x_{0}\right]_{\alpha\left(x_{0}\right)}$ such that $\beta\left(x_{0}, x_{1}\right) \geq 1$.

(e) If $x \in X$ and $\left\{x_{n}\right\}$ is a sequence in $X$ such that $\left\{x_{n}\right\} \rightarrow x$ and $\beta\left(x_{n}, x_{n+1}\right) \geq 1$ for all $n \in \mathbb{N}$, then $\beta\left(x_{n}, x\right) \geq 1$ for all $n \in \mathbb{N}$.

Then there exists $z \in X$ such that $z \in[S z]_{\alpha(z)} \cap[T z]_{\alpha(z)}$, that is, there exists a point $z \in X$ which is an $\alpha(z)$-fuzzy fixed point of $T$ and $S$.

In this section, we introduce the notion of $\alpha$-continuous fuzzy mapping and some generalized contractive conditions for $\alpha$-level sets via control functions and the Hausdorff metric for fuzzy sets. Also, we give existence theorems of common $\alpha$-fuzzy fixed points for a pair of fuzzy mappings satisfying such conditions.

Definition 16 A mapping $S: X \rightarrow \mathcal{F}(X)$ is an $\alpha$-continuous fuzzy mapping if, for all sequences $\left\{x_{n}\right\} \subseteq X$ such that $\left\{x_{n}\right\} \stackrel{d}{\rightarrow} x \in X$, we see that $\left\{\left[S x_{n}\right]_{\alpha\left(x_{n}\right)}\right\} \stackrel{H}{\rightarrow}[S x]_{\alpha(x)}$.

Let denote by $\Phi$ the family of all functions $\phi:[0, \infty)^{5} \rightarrow[0, \infty)$ such that there exist $M, N \in[0,1)$ verifying $M+2 N<1$ and

$$
\phi\left(t_{1}, t_{2}, t_{3}, t_{4}, t_{5}\right) \leq M \max \left\{t_{1}, t_{2}, t_{3}\right\}+N\left(t_{4}+t_{5}\right)
$$

for all $t_{1}, t_{2}, t_{3}, t_{4}, t_{5} \in[0, \infty)$. Examples of functions in $\Phi$ are

$$
\begin{aligned}
& \phi_{1}\left(t_{1}, t_{2}, t_{3}, t_{4}, t_{5}\right)=a_{1} t_{1}+a_{2} t_{2}+a_{3} t_{3}+a_{4} t_{4}+a_{5} t_{5}, \quad \text { where } a_{1}+a_{2}+a_{3}+a_{4}+a_{5}<1 ; \\
& \phi_{2}\left(t_{1}, t_{2}, t_{3}, t_{4}, t_{5}\right)=a \max \left\{t_{1}, t_{2}, t_{3}\right\}+b\left(t_{4}+t_{5}\right), \quad \text { where } a+2 b<1 .
\end{aligned}
$$

Next we present the main result of this paper.

Theorem 17 Let $(X, d)$ be a complete metric space and let $S, T: X \rightarrow \mathcal{F}(X), \alpha: X \rightarrow(0,1]$ and $\beta: X \times X \rightarrow[0, \infty)$ be four mappings such that the following properties are fulfilled.

(a) For $x \in X$, we have $[S x]_{\alpha(x)},[T x]_{\alpha(x)} \in \mathrm{CB}(X)$.

(b) There exists $\phi \in \Phi$ verifying, for $x, y \in X$,

$$
\begin{aligned}
\max \{\beta(x, y), \beta(y, x)\} \geq 1 & \\
\Rightarrow \quad H\left([S x]_{\alpha(x)},[T y]_{\alpha(y)}\right) \leq & \phi\left(d(x, y), d\left(x,[S x]_{\alpha(x)}\right), d\left(y,[T y]_{\alpha(y)}\right),\right. \\
& \left.d\left(x,[T y]_{\alpha(y)}\right), d\left(y,[S x]_{\alpha(x)}\right)\right) .
\end{aligned}
$$

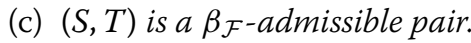


(d) There exist $x_{0} \in X$ and $x_{1} \in\left[S x_{0}\right]_{\alpha\left(x_{0}\right)}$ such that $\beta\left(x_{0}, x_{1}\right) \geq 1$.

(e) At least one of the following properties holds.

(e.1) $T$ and $S$ are $\alpha$-continuous fuzzy mappings.

(e.2) If $x \in X$ and $\left\{x_{n}\right\}$ is a sequence in $X$ such that $\left\{x_{n}\right\} \rightarrow x$ and $\beta\left(x_{n}, x_{n+1}\right) \geq 1$ for all $n \in \mathbb{N}$, then $\beta\left(x_{n}, x\right) \geq 1$ for all $n \in \mathbb{N}$.

Then there exists $z \in X$ such that $z \in[S z]_{\alpha(z)} \cap[T z]_{\alpha(z)}$, that is, there exists a point $z \in X$ which is an $\alpha(z)$-fuzzy fixed point of $T$ and $S$.

Proof Since $\phi \in \Phi$, there exist $M, N \in[0,1)$ verifying $M+2 N<1$ and (4). Let us define

$$
\mu=\frac{N}{1-M-N} \geq 0 \quad \text { and } \quad \lambda=\frac{M+N}{1-N} \geq 0 .
$$

Condition $M+2 N<1$ implies that

$$
0 \leq \mu \leq \lambda<1 .
$$

If $M=N=0$, then $\phi$ only takes the value zero. Therefore, as $\beta\left(x_{0}, x_{1}\right) \geq 1$, condition (5) yields

$$
d\left(x_{1},\left[T x_{1}\right]_{\alpha\left(x_{1}\right)}\right) \leq H\left(\left[S x_{0}\right]_{\alpha\left(x_{0}\right)},\left[T x_{0}\right]_{\alpha\left(x_{0}\right)}\right)=0 .
$$

This implies that $x_{1} \in\left[T x_{1}\right]_{\alpha\left(x_{1}\right)}$ and thus

$$
d\left(x_{1},\left[S x_{1}\right]_{\alpha\left(x_{1}\right)}\right) \leq H\left(\left[T x_{1}\right]_{\alpha\left(x_{1}\right)},\left[S x_{1}\right]_{\alpha\left(x_{1}\right)}\right) .
$$

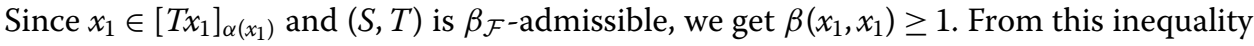
and (5), we get

$$
H\left(\left[S x_{1}\right]_{\alpha\left(x_{1}\right)},\left[T x_{1}\right]_{\alpha\left(x_{1}\right)}\right) \leq 0 .
$$

This implies that

$$
d\left(x_{1},\left[S x_{1}\right]_{\alpha\left(x_{1}\right)}\right) \leq 0 .
$$

So $x_{1} \in\left[S x_{1}\right]_{\alpha\left(x_{1}\right)}=\left[T x_{1}\right]_{\alpha\left(x_{1}\right)}$ and the proof is finished. Next, assume that $M+N>0$, that is, $0<\lambda<1$. Let $\left\{\varepsilon_{n}\right\}$ be the sequence of positive real numbers given by

$$
\varepsilon_{n}=\lambda^{n}(1-M-N)>0 \quad \text { for all } n \geq 1 .
$$

Starting from the points $x_{0} \in X$ and $x_{1} \in\left[S x_{0}\right]_{\alpha\left(x_{0}\right)}$ such that $\beta\left(x_{0}, x_{1}\right) \geq 1$, and using repeatedly Lemma 7 , we can determine successive points $x_{2}, x_{3}, x_{4}, \ldots$ in $X$ verifying the following properties:

$$
\begin{aligned}
a & =x_{1} \in A=\left[S x_{0}\right]_{\alpha\left(x_{0}\right)} \in \mathrm{CB}(X), \quad B=\left[T x_{1}\right]_{\alpha\left(x_{1}\right)} \in \mathrm{CB}(X), \quad \varepsilon_{1}>0 \\
& \Rightarrow \quad \exists x_{2} \in\left[T x_{1}\right]_{\alpha\left(x_{1}\right)} \quad \text { such that } \quad d\left(x_{1}, x_{2}\right) \leq H\left(\left[S x_{0}\right]_{\alpha\left(x_{0}\right)},\left[T x_{1}\right]_{\alpha\left(x_{1}\right)}\right)+\varepsilon_{1} ;
\end{aligned}
$$




$$
\begin{aligned}
a & =x_{2} \in A=\left[T x_{1}\right]_{\alpha\left(x_{1}\right)} \in \mathrm{CB}(X), \quad B=\left[S x_{2}\right]_{\alpha\left(x_{2}\right)} \in \mathrm{CB}(X), \quad \varepsilon_{2}>0 \\
& \Rightarrow \quad \exists x_{3} \in\left[S x_{2}\right]_{\alpha\left(x_{2}\right)} \quad \text { such that } \quad d\left(x_{2}, x_{3}\right) \leq H\left(\left[T x_{1}\right]_{\alpha\left(x_{1}\right)},\left[S x_{2}\right]_{\alpha\left(x_{2}\right)}\right)+\varepsilon_{2} .
\end{aligned}
$$

By induction, we can construct a sequence $\left\{x_{n}\right\}$ in $X$ verifying, for all $k \geq 0$,

$$
\begin{aligned}
& x_{2 k+1} \in\left[S x_{2 k}\right]_{\alpha\left(x_{2 k}\right)} \in \mathrm{CB}(X), \\
& x_{2 k+2} \in\left[T x_{2 k+1}\right]_{\alpha\left(x_{2 k+1}\right)} \in \mathrm{CB}(X), \\
& d\left(x_{2 k+1}, x_{2 k+2}\right) \leq H\left(\left[S x_{2 k}\right]_{\alpha\left(x_{2 k}\right)},\left[T x_{2 k+1}\right]_{\alpha\left(x_{2 k+1}\right)}\right)+\varepsilon_{2 k+1}, \\
& d\left(x_{2 k+2}, x_{2 k+3}\right) \leq H\left(\left[T x_{2 k+1}\right]_{\alpha\left(x_{2 k+1}\right)},\left[S x_{2 k+2}\right]_{\alpha\left(x_{2 k+2}\right)}\right)+\varepsilon_{2 k+2} .
\end{aligned}
$$

Since the pair $(S, T)$ is $\beta_{\mathcal{F}}$-admissible, then

$$
\begin{array}{ll}
x_{0} \in X, x_{1} \in\left[S x_{0}\right]_{\alpha\left(x_{0}\right)}, \quad \beta\left(x_{0}, x_{1}\right) \geq 1, \quad x_{2} \in\left[T x_{1}\right]_{\alpha\left(x_{1}\right)} \quad \Rightarrow \quad \beta\left(x_{1}, x_{2}\right) \geq 1 \\
x_{1} \in X, x_{2} \in\left[T x_{1}\right]_{\alpha\left(x_{1}\right)}, \quad \beta\left(x_{1}, x_{2}\right) \geq 1, \quad x_{3} \in\left[S x_{2}\right]_{\alpha\left(x_{2}\right)} \quad \Rightarrow \quad \beta\left(x_{2}, x_{3}\right) \geq 1 .
\end{array}
$$

By induction, it follows that

$$
\beta\left(x_{n}, x_{n+1}\right) \geq 1 \quad \text { for all } n \geq 0 .
$$

This implies that

$$
\max \left\{\beta\left(x_{n}, x_{n+1}\right), \beta\left(x_{n+1}, x_{n}\right)\right\} \geq 1 \quad \text { for all } n \geq 0 \text {. }
$$

In such a case, using (4), (5), (6), and (8), we have, for all $k \geq 0$,

$$
\begin{aligned}
d\left(x_{2 k+1}, x_{2 k+2}\right) \leq & H\left(\left[S x_{2 k}\right]_{\alpha\left(x_{2 k}\right)},\left[T x_{2 k+1}\right]_{\alpha\left(x_{2 k+1}\right)}\right)+\varepsilon_{2 k+1} \\
\leq & \phi\left(d\left(x_{2 k}, x_{2 k+1}\right), d\left(x_{2 k},\left[S x_{2 k}\right]_{\alpha\left(x_{2 k}\right)}\right), d\left(x_{2 k+1},\left[T x_{2 k+1}\right]_{\alpha\left(x_{2 k+1}\right)}\right),\right. \\
& \left.d\left(x_{2 k},\left[T x_{2 k+1}\right]_{\alpha\left(x_{2 k+1}\right)}\right), d\left(x_{2 k+1},\left[S x_{2 k}\right]_{\alpha\left(x_{2 k}\right)}\right)\right)+\varepsilon_{2 k+1} \\
\leq & M \max \left\{d\left(x_{2 k}, x_{2 k+1}\right), d\left(x_{2 k},\left[S x_{2 k}\right]_{\alpha\left(x_{2 k}\right)}\right), d\left(x_{2 k+1},\left[T x_{2 k+1}\right]_{\alpha\left(x_{2 k+1}\right)}\right)\right\} \\
& +N\left(d\left(x_{2 k},\left[T x_{2 k+1}\right]_{\alpha\left(x_{2 k+1}\right)}\right)+d\left(x_{2 k+1},\left[S x_{2 k}\right]_{\alpha\left(x_{2 k}\right)}\right)\right)+\varepsilon_{2 k+1} \\
\leq & M \max \left\{d\left(x_{2 k}, x_{2 k+1}\right), d\left(x_{2 k}, x_{2 k+1}\right), d\left(x_{2 k+1}, x_{2 k+2}\right)\right\} \\
& +N\left(d\left(x_{2 k}, x_{2 k+2}\right)+0\right)+\varepsilon_{2 k+1} \\
\leq & M \max \left\{d\left(x_{2 k}, x_{2 k+1}\right), d\left(x_{2 k+1}, x_{2 k+2}\right)\right\} \\
& +N\left(d\left(x_{2 k}, x_{2 k+1}\right)+d\left(x_{2 k+1}, x_{2 k+2}\right)\right)+\varepsilon_{2 k+1} .
\end{aligned}
$$

Therefore,

$$
\begin{aligned}
(1 & -N) d\left(x_{2 k+1}, x_{2 k+2}\right) \\
& \leq M \max \left\{d\left(x_{2 k}, x_{2 k+1}\right), d\left(x_{2 k+1}, x_{2 k+2}\right)\right\}+N d\left(x_{2 k}, x_{2 k+1}\right)+\varepsilon_{2 k+1} .
\end{aligned}
$$


If the maximum in (10) is $d\left(x_{2 k}, x_{2 k+1}\right)$, then

$$
\begin{aligned}
(1-N) d\left(x_{2 k+1}, x_{2 k+2}\right) & \leq(M+N) d\left(x_{2 k}, x_{2 k+1}\right)+\varepsilon_{2 k+1} \\
\Rightarrow d\left(x_{2 k+1}, x_{2 k+2}\right) & \leq \frac{M+N}{1-N} d\left(x_{2 k}, x_{2 k+1}\right)+\frac{\lambda^{2 k+1}(1-M-N)}{1-N} \\
& \leq \lambda d\left(x_{2 k}, x_{2 k+1}\right)+\lambda^{2 k+1},
\end{aligned}
$$

and if the maximum in (10) is $d\left(x_{2 k+1}, x_{2 k+2}\right)$, then

$$
\begin{aligned}
(1-N) d\left(x_{2 k+1}, x_{2 k+2}\right) & \leq M d\left(x_{2 k+1}, x_{2 k+2}\right)+N d\left(x_{2 k}, x_{2 k+1}\right)+\varepsilon_{2 k+1} \\
\Rightarrow d\left(x_{2 k+1}, x_{2 k+2}\right) & \leq \frac{N}{1-M-N} d\left(x_{2 k}, x_{2 k+1}\right)+\frac{\lambda^{2 k+1}(1-M-N)}{1-M-N} \\
& =\mu d\left(x_{2 k}, x_{2 k+1}\right)+\lambda^{2 k+1} .
\end{aligned}
$$

In any case, as $\mu \leq \lambda$, we deduce, combining (11) and (12), that for all $k \geq 0$,

$$
d\left(x_{2 k+1}, x_{2 k+2}\right) \leq \lambda d\left(x_{2 k}, x_{2 k+1}\right)+\lambda^{2 k+1} .
$$

Next, we analyze the other indices. Using a similar reasoning,

$$
\begin{aligned}
d\left(x_{2 k+2}, x_{2 k+3}\right) \leq & H\left(\left[T x_{2 k+1}\right]_{\alpha\left(x_{2 k+1}\right)},\left[S x_{2 k+2}\right]_{\alpha\left(x_{2 k+2}\right)}\right)+\varepsilon_{2 k+2} \\
\leq & M \max \left\{d\left(x_{2 k+2}, x_{2 k+1}\right), d\left(x_{2 k+2},\left[S x_{2 k+2}\right]_{\alpha\left(x_{2 k+2}\right)}\right),\right. \\
& \left.d\left(x_{2 k+1},\left[T x_{2 k+1}\right]_{\alpha\left(x_{2 k+1}\right)}\right)\right\} \\
& +N\left(d\left(x_{2 k+2},\left[T x_{2 k+1}\right]_{\alpha\left(x_{2 k+1}\right)}\right)+d\left(x_{2 k+1},\left[S x_{2 k+2}\right]_{\alpha\left(x_{2 k+2}\right)}\right)\right)+\varepsilon_{2 k+2} \\
\leq & M \max \left\{d\left(x_{2 k+1}, x_{2 k+2}\right), d\left(x_{2 k+2}, x_{2 k+3}\right), d\left(x_{2 k+1}, x_{2 k+2}\right)\right\} \\
& +N\left(0+d\left(x_{2 k+1}, x_{2 k+3}\right)\right)+\varepsilon_{2 k+2} \\
\leq & M \max \left\{d\left(x_{2 k+1}, x_{2 k+2}\right), d\left(x_{2 k+2}, x_{2 k+3}\right)\right\} \\
& +N\left(d\left(x_{2 k+1}, x_{2 k+2}\right)+d\left(x_{2 k+2}, x_{2 k+3}\right)\right)+\varepsilon_{2 k+2} .
\end{aligned}
$$

Therefore,

$$
\begin{aligned}
& (1-N) d\left(x_{2 k+2}, x_{2 k+3}\right) \\
& \quad \leq M \max \left\{d\left(x_{2 k+1}, x_{2 k+2}\right), d\left(x_{2 k+2}, x_{2 k+3}\right)\right\}+N d\left(x_{2 k+1}, x_{2 k+2}\right)+\varepsilon_{2 k+2} .
\end{aligned}
$$

If the maximum in (14) is $d\left(x_{2 k+1}, x_{2 k+2}\right)$, then

$$
\begin{aligned}
(1-N) d\left(x_{2 k+2}, x_{2 k+3}\right) & \leq(M+N) d\left(x_{2 k+1}, x_{2 k+2}\right)+\varepsilon_{2 k+2} \\
\Rightarrow d\left(x_{2 k+2}, x_{2 k+3}\right) & \leq \frac{M+N}{1-N} d\left(x_{2 k+1}, x_{2 k+2}\right)+\frac{\lambda^{2 k+2}(1-M-N)}{1-N} \\
& \leq \lambda d\left(x_{2 k+1}, x_{2 k+2}\right)+\lambda^{2 k+2},
\end{aligned}
$$


and if the maximum in (14) is $d\left(x_{2 k+2}, x_{2 k+3}\right)$, then

$$
\begin{aligned}
(1-N) d\left(x_{2 k+2}, x_{2 k+3}\right) & \leq M d\left(x_{2 k+2}, x_{2 k+3}\right)+N d\left(x_{2 k+1}, x_{2 k+2}\right)+\varepsilon_{2 k+2} \\
\Rightarrow \quad d\left(x_{2 k+2}, x_{2 k+3}\right) & \leq \frac{N}{1-M-N} d\left(x_{2 k+1}, x_{2 k+2}\right)+\frac{\lambda^{2 k+2}(1-M-N)}{1-M-N} \\
& =\mu d\left(x_{2 k+1}, x_{2 k+2}\right)+\lambda^{2 k+2} .
\end{aligned}
$$

In any case, as $\mu \leq \lambda$, we deduce, combining (15) and (16), that for all $k \geq 0$,

$$
d\left(x_{2 k+2}, x_{2 k+3}\right) \leq \lambda d\left(x_{2 k+1}, x_{2 k+2}\right)+\lambda^{2 k+1} .
$$

And combining (13) and (17), we conclude that

$$
d\left(x_{n+1}, x_{n+2}\right) \leq \lambda d\left(x_{n}, x_{n+1}\right)+\lambda^{n} \quad \text { for all } n \geq 0 .
$$

By Lemma 14, $\left\{x_{n}\right\}$ is a Cauchy sequence in $(X, d)$. As the metric space $X$ is complete, there exists $z \in X$ such that $\left\{x_{n}\right\} \rightarrow z$. We will show that $z$ verifies $z \in[S z]_{\alpha(z)} \cap[T z]_{\alpha(z)}$ distinguishing the cases of hypothesis $(\mathrm{d})$.

Case (e.1). Assume that $T$ and $S$ are $\alpha$-continuous fuzzy mappings. In such a case,

$$
\left\{\left[S x_{n}\right]_{\alpha\left(x_{n}\right)}\right\} \stackrel{H}{\rightarrow}[S z]_{\alpha(z)} \text { and } \quad\left\{\left[T x_{n}\right]_{\alpha\left(x_{n}\right)}\right\} \stackrel{H}{\rightarrow}[T z]_{\alpha(z)}
$$

By (9) and Lemma 5,

$$
\begin{aligned}
& H\left(\left[S x_{2 k}\right]_{\alpha\left(x_{2 k}\right)},\left[T x_{2 k+1}\right]_{\alpha\left(x_{2 k+1}\right)}\right) \\
& \leq M \max \left\{d\left(x_{2 k}, x_{2 k+1}\right), d\left(x_{2 k},\left[S x_{2 k}\right]_{\alpha\left(x_{2 k}\right)}\right), d\left(x_{2 k+1},\left[T x_{2 k+1}\right]_{\alpha\left(x_{2 k+1}\right)}\right)\right\} \\
& \quad+ N\left(d\left(x_{2 k},\left[T x_{2 k+1}\right]_{\alpha\left(x_{2 k+1}\right)}\right)+d\left(x_{2 k+1},\left[S x_{2 k}\right]_{\alpha\left(x_{2 k}\right)}\right)\right) \\
& \leq M \max \left\{d\left(x_{2 k}, x_{2 k+1}\right), H\left(\left[T x_{2 k-1}\right]_{\alpha\left(x_{2 k-1}\right)},\left[S x_{2 k}\right]_{\alpha\left(x_{2 k}\right)}\right),\right. \\
&\left.H\left(\left[S x_{2 k}\right]_{\alpha\left(x_{2 k}\right)},\left[T x_{2 k+1}\right]_{\alpha\left(x_{2 k+1}\right)}\right)\right\} \\
&+N\left(H\left(\left[T x_{2 k-1}\right]_{\alpha\left(x_{2 k-1}\right)},\left[T x_{2 k+1}\right]_{\alpha\left(x_{2 k+1}\right)}\right)+H\left(\left[S x_{2 k}\right]_{\alpha\left(x_{2 k}\right)},\left[S x_{2 k}\right]_{\alpha\left(x_{2 k}\right)}\right)\right) .
\end{aligned}
$$

Letting $k \rightarrow \infty$ in the previous inequality, we deduce that

$$
\begin{aligned}
H\left([S z]_{\alpha(z)},[T z]_{\alpha(z)}\right) \leq & M \max \left\{0, H\left([T z]_{\alpha(z)},[S z]_{\alpha(z)}\right), H\left([S z]_{\alpha(z)},[T z]_{\alpha(z)}\right)\right\} \\
& +N(0+0) \\
= & M H\left([T z]_{\alpha(z)},[S z]_{\alpha(z)}\right)
\end{aligned}
$$

which is only possible when $[S z]_{\alpha(z)}=[T z]_{\alpha(z)}$. Furthermore, as

$$
d\left(x_{2 k},\left[S x_{2 k}\right]_{\alpha\left(x_{2 k}\right)}\right) \leq H\left(\left[T x_{2 k-1}\right]_{\alpha\left(x_{2 k-1}\right)},\left[S x_{2 k}\right]_{\alpha\left(x_{2 k}\right)}\right) \text { for all } k
$$

we also deduce that $d\left(z,[S z]_{\alpha(z)}\right)=0$, so $z \in[S z]_{\alpha(z)}=[T z]_{\alpha(z)}$. 
Case (e.2). Assume that if $x \in X$ and $\left\{x_{n}\right\}$ is a sequence in $X$ such that $\left\{x_{n}\right\} \rightarrow x$ and $\beta\left(x_{n}, x_{n+1}\right) \geq 1$ for all $n \in \mathbb{N}$, then $\beta\left(x_{n}, x\right) \geq 1$ for all $n \in \mathbb{N}$. In this case, we have $\beta\left(x_{n}, z\right) \geq 1$ for all $n \geq 0$, so

$$
\max \left\{\beta\left(x_{n}, z\right), \beta\left(z, x_{n}\right)\right\} \geq 1 \quad \text { for all } n \geq 0 .
$$

Let apply Lemma 5 and the contractive condition (5) to obtain

$$
\begin{aligned}
d\left(x_{2 k},[S z]_{\alpha(z)}\right) \leq & H\left(\left[T x_{2 k-1}\right]_{\alpha\left(x_{2 k-1}\right)},[S z]_{\alpha(z)}\right)=H\left([S z]_{\alpha(z)},\left[T x_{2 k-1}\right]_{\alpha\left(x_{2 k-1}\right)}\right) \\
\leq & \phi\left(d\left(z, x_{2 k-1}\right), d\left(z,[S z]_{\alpha(z)}\right), d\left(x_{2 k-1},\left[T x_{2 k-1}\right]_{\alpha\left(x_{2 k-1}\right)}\right),\right. \\
& \left.d\left(z,\left[T x_{2 k-1}\right]_{\alpha\left(x_{2 k-1}\right)}\right), d\left(x_{2 k-1},[S z]_{\alpha(z)}\right)\right) \\
\leq & M \max \left\{d\left(z, x_{2 k-1}\right), d\left(z,[S z]_{\alpha(z)}\right), d\left(x_{2 k-1},\left[T x_{2 k-1}\right]_{\alpha\left(x_{2 k-1}\right)}\right)\right\} \\
& +N\left(d\left(z,\left[T x_{2 k-1}\right]_{\alpha\left(x_{2 k-1}\right)}\right)+d\left(x_{2 k-1},[S z]_{\alpha(z)}\right)\right) \\
\leq & M \max \left\{d\left(z, x_{2 k-1}\right), d\left(z,[S z]_{\alpha(z)}\right), d\left(x_{2 k-1}, x_{2 k}\right)\right\} \\
& +N\left(d\left(z, x_{2 k}\right)+d\left(x_{2 k-1},[S z]_{\alpha(z)}\right)\right) .
\end{aligned}
$$

Letting $k \rightarrow \infty$, by Proposition 6 we have

$$
\begin{aligned}
d\left(z,[S z]_{\alpha(z)}\right) & \leq M \max \left\{0, d\left(z,[S z]_{\alpha(z)}\right), 0\right\}+N\left(0+d\left(z,[S z]_{\alpha(z)}\right)\right) \\
& =(M+N) d\left(z,[S z]_{\alpha(z)}\right) .
\end{aligned}
$$

Taking into account that $M+N \leq M+2 N<1$, the previous inequality leads to $d(z$, $\left.[S z]_{\alpha(z)}\right)=0$, that is, $z \in \overline{[S z]_{\alpha(z)}}=[S z]_{\alpha(z)}$. Similarly, using

$$
d\left(x_{2 k+1},[T z]_{\alpha(z)}\right) \leq H\left(\left[S x_{2 k}\right]_{\alpha\left(x_{2 k-1}\right)},[T z]_{\alpha(z)}\right)
$$

it is possible to prove that $z \in \overline{[T z]_{\alpha(z)}}=[T z]_{\alpha(z)}$, and the proof is finished.

Example 18 Let $X=[0, \infty)$ be endowed with the Euclidean metric $d(x, y)=|x-y|$ for all $x, y \in X$. Clearly, $(X, d)$ is a complete metric space. Let $\alpha_{1}, \alpha_{2}, \alpha_{3} \in(0,1)$ be three real numbers such that $\alpha_{1}<\alpha_{2}<\alpha_{3}$. Let consider the mappings $S, T: X \rightarrow \mathcal{F}(X), \alpha: X \rightarrow(0,1]$ and $\beta: X \times X \rightarrow[0, \infty)$ be given by

$$
\begin{aligned}
& \alpha(x)=\alpha_{1} ; \quad \beta(x, y)= \begin{cases}1, & \text { if } x, y \in[0,2), \\
0, & \text { otherwise; }\end{cases} \\
& T(x)(t)= \begin{cases}\alpha_{2}, & \text { if } x \in[0,1] \text { and } t=x / 4, \\
\alpha_{2}, & \text { if } x>1 \text { and } t=1 / 4, \\
0, & \text { otherwise; }\end{cases} \\
& S(x)(t)= \begin{cases}\alpha_{3}, & \text { if } t=0, \\
0, & \text { otherwise. }\end{cases}
\end{aligned}
$$

The following facts are easy to check. 
- For all $x \in X$,

$$
[T(x)]_{\alpha(x)}=\left\{\begin{array}{ll}
\{x / 4\}, & \text { if } x \in[0,1], \\
\{1 / 4\}, & \text { if } x>1 ;
\end{array} \quad[S(x)]_{\alpha(x)}=\{0\} .\right.
$$

As a result, $[T(x)]_{\alpha(x)}$ and $[S(x)]_{\alpha(x)}$ are nonempty, closed, bounded subsets of $(X, d)$.

- The pair $(S, T)$ is a $\beta_{\mathcal{F}}$-admissible pair. To prove it, let $x \in X$ and $y \in[S x]_{\alpha(x)}$ be such that $\beta(x, y) \geq 1$. Hence $x \in[0,1]$ and $y=0$. As a result, if $z \in[T y]_{\alpha(y)}=[T(0)]_{\alpha(0)}=\{0\}$, then $\beta(y, z)=\beta(0,0)=1$. In the other hand, let $x \in X$ and $y \in[T x]_{\alpha(x)}$ be such that $\beta(x, y) \geq 1$. Therefore, $x, y \in[0,2)$ and $y \in[T x]_{\alpha(x)} \subseteq\{x / 4,1 / 4\} \subseteq[0,1]$. If $z \in[S y]_{\alpha(y)}=\{0\}$, then $\beta(y, z)=\beta(y, 0)=1$.

- If we take $x_{0}=1$ and $x_{1}=0 \in\left[S x_{0}\right]_{\alpha\left(x_{0}\right)}$, then $\beta\left(x_{0}, x_{1}\right) \geq 1$.

- We claim that $T$ and $S$ are $\alpha$-continuous fuzzy mappings. Indeed, let $\left\{x_{n}\right\} \subseteq X$ be a sequence such that $\left\{x_{n}\right\} \rightarrow x \in X$. Hence

$$
\left[S x_{n}\right]_{\alpha\left(x_{n}\right)}=\{0\} \quad \text { for all } n \in \mathbb{N} \Rightarrow\left\{\left[S x_{n}\right]_{\alpha\left(x_{n}\right)}\right\} \stackrel{H}{\rightarrow}\{0\}=[S x]_{\alpha(x)} .
$$

Similarly, as

$$
\left[T x_{n}\right]_{\alpha\left(x_{n}\right)}= \begin{cases}\left\{x_{n} / 4\right\}, & \text { if } x_{n} \in[0,1] \\ \{1 / 4\}, & \text { if } x_{n}>1\end{cases}
$$

for all $n \in \mathbb{N}$, then

$$
\left\{\left[T x_{n}\right]_{\alpha\left(x_{n}\right)}\right\} \stackrel{H}{\rightarrow}[T x]_{\alpha(x)}= \begin{cases}\{x / 4\}, & \text { if } x \in[0,1], \\ \{1 / 4\}, & \text { if } x>1 .\end{cases}
$$

- Let us show that $T$ and $S$ satisfy the contractivity condition (5) using the function $\phi \in \Phi$ given by

$$
\phi\left(t_{1}, t_{2}, t_{3}, t_{4}, t_{5}\right)=\frac{1}{10} t_{1}+\frac{1}{20} t_{2}+\frac{1}{30} t_{3}+\frac{1}{3} t_{4}
$$

for all $t_{1}, t_{2}, t_{3}, t_{4}, t_{5} \in[0, \infty)$. Indeed, let $x, y \in X$ be such that $\max \{\beta(x, y), \beta(y, x)\} \geq 1$. It follows that $x, y \in[0,2)$. Then

$$
\begin{aligned}
H\left([S x]_{\alpha(x)},[T y]_{\alpha(y)}\right) & =\left\{\begin{array}{ll}
H(\{0\},\{y / 4\}), & \text { if } y \in[0,1], \\
H(\{0\},\{1 / 4\}), & \text { if } y \in(1,2)
\end{array}\right\} \\
& = \begin{cases}y / 4, & \text { if } y \in[0,1], \\
1 / 4, & \text { if } y \in(1,2) .\end{cases}
\end{aligned}
$$

As $d\left(y,[S x]_{\alpha(x)}\right)=d(y,\{0\})=y$, then

$$
\begin{aligned}
H\left([S x]_{\alpha(x),}[T y]_{\alpha(y)}\right)= & \left\{\begin{array}{ll}
y / 4, & \text { if } y \in[0,1], \\
1 / 4, & \text { if } y \in(1,2)
\end{array}\right\} \leq \frac{y}{4}=\frac{1}{4} d\left(y,[S x]_{\alpha(x)}\right) \\
\leq & \phi\left(d(x, y), d\left(x,[S x]_{\alpha(x)}\right), d\left(y,[T y]_{\alpha(y)}\right),\right. \\
& \left.d\left(x,[T y]_{\alpha(y)}\right), d\left(y,[S x]_{\alpha(x)}\right)\right) .
\end{aligned}
$$


- The function $\beta$ does not satisfy condition (e) in Theorem 15. Indeed, if $x_{n}=2-1 / n$ for all $n \geq 1$, then $\left\{x_{n}\right\} \rightarrow 2$ and $\beta\left(x_{n}, x_{n+1}\right)=1$ for all $n \geq 1$. However, $\beta\left(x_{n}, 2\right)=0<1$ for all $n \geq 1$.

As a consequence of the last bullet item, Theorem 15 is not applicable to $T$ and $S$. However, Theorem 17 guarantees that there exists $z \in X$ which is an $\alpha(z)$-fuzzy fixed point of $T$ and $S$ (in this case, $z=0$ ).

Notice that, as the previous example illustrates, one of the main advantages of the contractivity condition (5) versus (3) is that we only have to prove it for pairs $(x, y) \in X \times X$ such that $\max \{\beta(x, y), \beta(y, x)\} \geq 1$, but not necessarily for all $x, y \in X$.

In the following example, we use similar arguments but involving nonlinear mappings.

Example 19 Let $X$ be the real interval $[0,10]$ endowed with the Euclidean metric $d(x, y)=$ $|x-y|$ for all $x, y \in X$. Given five real numbers $\alpha_{1}, \alpha_{2}, \alpha_{3}, \lambda, M \in(0,1)$ such that $\alpha_{1}<\alpha_{2}<\alpha_{3}$ and $8 \lambda<M$, let consider the mappings $\alpha: X \rightarrow(0,1], \beta: X \times X \rightarrow[0, \infty), S, T: X \rightarrow \mathcal{F}(X)$ and $\phi:[0, \infty)^{5} \rightarrow[0, \infty)$ given by

$$
\begin{aligned}
& \alpha(x)=\alpha_{1} ; \quad \beta(x, y)= \begin{cases}1, & \text { if } x, y \in[0,1), \\
0, & \text { otherwise; }\end{cases} \\
& S(x)(t)= \begin{cases}\alpha_{2}, & \text { if } t=\lambda x^{2}, \\
0, & \text { otherwise; }\end{cases} \\
& T(x)(t)= \begin{cases}\alpha_{3}, & \text { if } t=\lambda x^{4}, \\
0, & \text { otherwise; }\end{cases} \\
& \phi\left(t_{1}, t_{2}, t_{3}, t_{4}, t_{5}\right)= \begin{cases}M \log \left(\max \left\{1+t_{1}, 1+t_{2}, 1+t_{3}\right\}\right), & \text { if } t_{1}, t_{2}, t_{3} \in[0,1], \\
0, & \text { otherwise. }\end{cases}
\end{aligned}
$$

The following properties hold.

- For all $x \in X,[S(x)]_{\alpha(x)}=\left\{\lambda x^{2}\right\}$ and $[T(x)]_{\alpha(x)}=\left\{\lambda x^{4}\right\}$, which are nonempty, closed, bounded subsets of $(X, d)$.

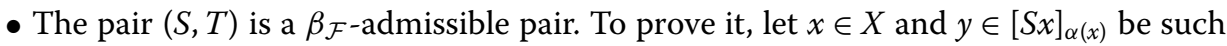
that $\beta(x, y) \geq 1$. Hence $x \in[0,1)$ and $y=\lambda x^{2} \in[0,1)$. If $z \in[T y]_{\alpha(y)}=\left[T\left(\lambda x^{2}\right)\right]_{\alpha\left(\lambda x^{2}\right)}=\left\{\lambda^{4} x^{8}\right\}$, then $\beta(y, z)=\beta\left(\lambda x^{2}, \lambda^{4} x^{8}\right)=1$ because $\lambda x^{2}, \lambda^{4} x^{8} \in[0,1)$. In the other hand, let $x \in X$ and $y \in[T x]_{\alpha(x)}$ be such that $\beta(x, y) \geq 1$. Therefore, $x, y \in[0,1)$ and $y=\lambda x^{4}$. If $z \in[S y]_{\alpha(y)}=$ $\left[S\left(\lambda x^{4}\right)\right]_{\alpha\left(\lambda x^{4}\right)}=\left\{\lambda^{2} x^{8}\right\}$, then $\beta(y, z)=\beta\left(\lambda x^{4}, \lambda^{2} x^{8}\right)=1$.

- If we take $x_{0}=1 / 2$ and $x_{1}=\lambda / 4 \in\left[S x_{0}\right]_{\alpha\left(x_{0}\right)}$, then $\beta\left(x_{0}, x_{1}\right) \geq 1$.

- We claim that $T$ and $S$ are $\alpha$-continuous fuzzy mappings. Indeed, let $\left\{x_{n}\right\} \subseteq X$ be a sequence such that $\left\{x_{n}\right\} \rightarrow x \in X$. Hence $\left[S x_{n}\right]_{\alpha\left(x_{n}\right)}=\left\{\lambda x_{n}^{2}\right\}$ and $\left[T x_{n}\right]_{\alpha\left(x_{n}\right)}=\left\{\lambda x_{n}^{4}\right\}$ for all $n \in \mathbb{N}$. As a result,

$$
\left\{\left[S x_{n}\right]_{\alpha\left(x_{n}\right)}\right) \stackrel{H}{\rightarrow}\left\{\lambda x^{2}\right\}=[S x]_{\alpha(x)} \quad \text { and } \quad\left\{\left[T x_{n}\right]_{\alpha\left(x_{n}\right)}\right\} \stackrel{H}{\rightarrow}\left\{\lambda x^{4}\right\}=[T x]_{\alpha(x)} .
$$

- Let us show that $\phi \in \Phi$. Recall that

$$
\frac{t}{2} \leq \log (1+t) \leq t \quad \text { for all } t \in[0,1]
$$


Hence, for all $t_{1}, t_{2}, t_{3}, t_{4}, t_{5} \in[0, \infty)$ such that $t_{1}, t_{2}, t_{3} \in[0,1]$,

$$
\begin{aligned}
\phi\left(t_{1}, t_{2}, t_{3}, t_{4}, t_{5}\right) & =M \log \left(\max \left\{1+t_{1}, 1+t_{2}, 1+t_{3}\right\}\right) \\
& =M \log \left(1+\max \left\{t_{1}, t_{2}, t_{3}\right\}\right) \leq M \max \left\{t_{1}, t_{2}, t_{3}\right\} .
\end{aligned}
$$

As $M<1$, then $\phi \in \Phi$.

- We claim that $T$ and $S$ satisfy the contractivity condition (5) using the function $\phi \in \Phi$. Indeed, let $x, y \in X$ be such that $\max \{\beta(x, y), \beta(y, x)\} \geq 1$. It follows that $x, y \in[0,1)$. Notice that

$$
d(x, y)=|x-y|, d\left(x,[S x]_{\alpha(x)}\right)=\left|x-\lambda x^{2}\right|, d\left(y,[T y]_{\alpha(y)}\right)=\left|y-\lambda y^{4}\right| \in[0,1]
$$

and also

$$
\lambda y^{4} \leq \lambda y^{2} \leq y^{2} \Rightarrow\left|y-y^{2}\right|=y-y^{2} \leq y-\lambda y^{4}=\left|y-\lambda y^{4}\right| .
$$

Then, by (19), (20), and (21),

$$
\begin{aligned}
H\left([S x]_{\alpha(x)},[T y]_{\alpha(y)}\right)= & H\left(\left\{\lambda x^{2}\right\},\left\{\lambda y^{4}\right\}\right)=\left|\lambda x^{2}-\lambda y^{4}\right|=\lambda\left|x^{2}-y^{4}\right| \\
= & \lambda\left|x+y^{2}\right|\left|x-y^{2}\right| \leq 2 \lambda\left|x-y^{2}\right| \leq 2 \lambda\left(|x-y|+\left|y-y^{2}\right|\right) \\
\leq & 2 \lambda\left(|x-y|+\left|y-\lambda y^{4}\right|\right) \leq 4 \lambda \max \left\{|x-y|,\left|y-\lambda y^{4}\right|\right\} \\
\leq & 8 \lambda \frac{\max \left\{d(x, y), d\left(y,[T y]_{\alpha(y)}\right), d\left(x,[S x]_{\alpha(x)}\right)\right\}}{2} \\
\leq & M \log \left(1+\max \left\{d(x, y), d\left(y,[T y]_{\alpha(y)}\right), d\left(x,[S x]_{\alpha(x)}\right)\right\}\right) \\
= & \phi\left(d(x, y), d\left(x,[S x]_{\alpha(x)}\right), d\left(y,[T y]_{\alpha(y)}\right),\right. \\
& \left.d\left(x,[T y]_{\alpha(y)}\right), d\left(y,[S x]_{\alpha(x)}\right)\right) .
\end{aligned}
$$

- The function $\beta$ does not satisfy condition (e) in Theorem 15 . Indeed, if $x_{n}=1-1 /(n+2)$ for all $n \geq 1$, then $\left\{x_{n}\right\} \rightarrow 1$ and $\beta\left(x_{n}, x_{n+1}\right)=1$ for all $n \geq 1$. However, $\beta\left(x_{n}, 1\right)=0<1$ for all $n \geq 1$.

As a consequence of the last bullet item, Theorem 15 is not applicable to $T$ and $S$. However, Theorem 17 guarantees that there exists $z \in X$ which is an $\alpha(z)$-fuzzy fixed point of $T$ and $S$ (in this case, $z=0$ ).

The following consequence is another way to interpret the contractivity condition that can be useful.

Corollary 20 Let $(X, d)$ be a complete metric space and let $S, T: X \rightarrow \mathcal{F}(X), \alpha: X \rightarrow(0,1]$ and $\beta: X \times X \rightarrow[0, \infty)$ be four mappings such that the following properties are fulfilled.

(a) For $x, y \in X$, we have $[S x]_{\alpha(x)},[T y]_{\alpha(y)} \in \mathrm{CB}(X)$.

(b) There exists $\phi \in \Phi$ verifying

$$
\begin{aligned}
& \max \{\beta(x, y), \beta(y, x)\} H\left([S x]_{\alpha(x)},[T y]_{\alpha(y)}\right) \\
& \quad \leq \phi\left(d(x, y), d\left(x,[S x]_{\alpha(x)}\right), d\left(y,[T y]_{\alpha(y)}\right), d\left(x,[T y]_{\alpha(y)}\right), d\left(y,[S x]_{\alpha(x)}\right)\right)
\end{aligned}
$$

for all $x, y \in X$. 
(c) $(S, T)$ is a $\beta_{\mathcal{F}}$-admissible pair.

(d) There exist $x_{0} \in X$ and $x_{1} \in\left[S x_{0}\right]_{\alpha\left(x_{0}\right)}$ such that $\beta\left(x_{0}, x_{1}\right) \geq 1$.

(e) At least one of the following properties holds.

(e.1) $T$ and $S$ are $\alpha$-continuous fuzzy mappings.

(e.2) If $x \in X$ and $\left\{x_{n}\right\}$ is a sequence in $X$ such that $\left\{x_{n}\right\} \rightarrow x$ and $\beta\left(x_{n}, x_{n+1}\right) \geq 1$ for all $n \in \mathbb{N}$, then $\beta\left(x_{n}, x\right) \geq 1$ for all $n \in \mathbb{N}$.

Then there exists $z \in X$ such that $z \in[S z]_{\alpha(z)} \cap[T z]_{\alpha(z)}$, that is, there exists a point $z \in X$ which is an $\alpha(z)$-fuzzy fixed point of $T$ and $S$.

Proof It is easy to see that condition (22) implies condition (5). Indeed, if $x, y \in X$ are such that $\max \{\beta(x, y), \beta(y, x)\} \geq 1$, then, by hypothesis (b), we obtain

$$
\begin{aligned}
H\left([S x]_{\alpha(x)},[T y]_{\alpha(y)}\right) \leq & \max \{\beta(x, y), \beta(y, x)\} H\left([S x]_{\alpha(x)},[T y]_{\alpha(y)}\right) \\
\leq & \phi\left(d(x, y), d\left(x,[S x]_{\alpha(x)}\right), d\left(y,[T y]_{\alpha(y)}\right),\right. \\
& \left.d\left(x,[T y]_{\alpha(y)}\right), d\left(y,[S x]_{\alpha(x)}\right)\right) .
\end{aligned}
$$

Therefore, all hypotheses of Theorem 20 are satisfied, and the desired result follows immediately from this theorem.

Corollary 21 If $a_{3}=a_{4}$ in assumption of Theorem 15, then Theorem 15 follows from Corollary 20.

Proof Letting $M=a_{1}+a_{2}+a_{5}$ and $N=a_{3}=a_{4}$, we have

$$
M+2 N=\left(a_{1}+a_{2}+a_{5}\right)+2 a_{3}=a_{1}+a_{2}+a_{3}+a_{4}+a_{5}<1,
$$

and, for all $x, y \in X$ such that $[S x]_{\alpha(x)},[T y]_{\alpha(y)} \in \mathrm{CB}(X)$,

$$
\begin{aligned}
\max \{ & \beta(x, y), \beta(y, x)\} H\left([S x]_{\alpha(x)},[T y]_{\alpha(y)}\right) \\
\leq & a_{1} d\left(x,[S x]_{\alpha(x)}\right)+a_{2} d\left(y,[T y]_{\alpha(y)}\right)+a_{3} d\left(x,[T y]_{\alpha(y)}\right)+a_{4} d\left(y,[S x]_{\alpha(x)}\right)+a_{5} d(x, y) \\
\leq & a_{5} \max \left\{d(x, y), d\left(x,[S x]_{\alpha(x)}\right), d\left(y,[T y]_{\alpha(y)}\right)\right\} \\
& +a_{1} \max \left\{d(x, y), d\left(x,[S x]_{\alpha(x)}\right), d\left(y,[T y]_{\alpha(y)}\right)\right\} \\
& +a_{2} \max \left\{d(x, y), d\left(x,[S x]_{\alpha(x)}\right), d\left(y,[T y]_{\alpha(y)}\right)\right\}+N d\left(x,[T y]_{\alpha(y)}\right)+N d\left(y,[S x]_{\alpha(x)}\right) \\
= & \left(a_{1}+a_{2}+a_{5}\right) \max \left\{d(x, y), d\left(x,[S x]_{\alpha(x)}\right), d\left(y,[T y]_{\alpha(y)}\right)\right\} \\
& +N\left(d\left(x,[T y]_{\alpha(y)}\right)+d\left(y,[S x]_{\alpha(x)}\right)\right) \\
= & M \max \left\{d(x, y), d\left(x,[S x]_{\alpha(x)}\right), d\left(y,[T y]_{\alpha(y)}\right)\right\}+N\left(d\left(x,[T y]_{\alpha(y)}\right)+d\left(y,[S x]_{\alpha(x)}\right)\right) .
\end{aligned}
$$

Using $\phi\left(t_{1}, t_{2}, t_{3}, t_{4}, t_{5}\right)=M \max \left\{t_{1}, t_{2}, t_{3}\right\}+N\left(t_{4}+t_{5}\right)$ for all $t_{1}, t_{2}, t_{3}, t_{4}, t_{5} \in[0, \infty)$, we conclude that condition (3) implies (5).

Remark 22 If we have supposed $3 M+2 N<1$, then Theorem 15 and Corollary 20 (case (e.2)) would have been equivalent because, in such a case, condition (5) also implies (3). 
Indeed, if we take $a_{1}=a_{2}=a_{5}=M$ and $a_{3}=a_{4}=N$, then

$$
\begin{aligned}
\max & \{\beta(x, y), \beta(y, x)\} H\left([S x]_{\alpha(x)},[T y]_{\alpha(y)}\right) \\
& \leq M \max \left\{d(x, y), d\left(x,[S x]_{\alpha(x)}\right), d\left(y,[T y]_{\alpha(y)}\right)\right\}+N\left(d\left(x,[T y]_{\alpha(y)}\right)+d\left(y,[S x]_{\alpha(x)}\right)\right) \\
& \leq M\left(d(x, y)+d\left(x,[S x]_{\alpha(x)}\right)+d\left(y,[T y]_{\alpha(y)}\right)\right)+N\left(d\left(x,[T y]_{\alpha(y)}\right)+d\left(y,[S x]_{\alpha(x)}\right)\right) \\
& =M d(x, y)+M d\left(x,[S x]_{\alpha(x)}\right)+M d\left(y,[T y]_{\alpha(y)}\right)+N d\left(x,[T y]_{\alpha(y)}\right)+N d\left(y,[S x]_{\alpha(x)}\right) \\
& =a_{1} d\left(x,[S x]_{\alpha(x)}\right)+a_{2} d\left(y,[T y]_{\alpha(y)}\right)+a_{3} d\left(x,[T y]_{\alpha(y)}\right)+a_{4} d\left(y,[S x]_{\alpha(x)}\right)+a_{5} d(x, y) .
\end{aligned}
$$

Therefore, the best thing to do to take advantage of condition (5) is that we only suppose $M+2 N<1$.

In the following results, we present several contractivity conditions that can be reduced to (3).

Corollary 23 Let $(X, d)$ be a complete metric space and let $S, T: X \rightarrow \mathcal{F}(X), \alpha: X \rightarrow(0,1]$ and $\beta: X \times X \rightarrow[0, \infty)$ be four mappings such that the following properties are fulfilled.

(a) For $x, y \in X$, we have $[S x]_{\alpha(x)},[T y]_{\alpha(y)} \in \mathrm{CB}(X)$.

(b) There exist $\phi \in \Phi$ and $\tau \geq 1$ verifying

$$
\begin{aligned}
& \left(\tau+H\left([S x]_{\alpha(x)},[T y]_{\alpha(y)}\right)\right)^{\max \{\beta(x, y), \beta(y, x)\}} \\
& \quad \leq \tau+\phi\left(d(x, y), d\left(x,[S x]_{\alpha(x)}\right), d\left(y,[T y]_{\alpha(y)}\right), d\left(x,[T y]_{\alpha(y)}\right), d\left(y,[S x]_{\alpha(x)}\right)\right)
\end{aligned}
$$

for all $x, y \in X$.

(c) $(S, T)$ is a $\beta_{\mathcal{F}}$-admissible pair.

(d) There exist $x_{0} \in X$ and $x_{1} \in\left[S x_{0}\right]_{\alpha\left(x_{0}\right)}$ such that $\beta\left(x_{0}, x_{1}\right) \geq 1$.

(e) At least one of the following properties holds.

(e.1) $T$ and $S$ are $\alpha$-continuous fuzzy mappings.

(e.2) If $x \in X$ and $\left\{x_{n}\right\}$ is a sequence in $X$ such that $\left\{x_{n}\right\} \rightarrow x$ and $\beta\left(x_{n}, x_{n+1}\right) \geq 1$ for all $n \in \mathbb{N}$, then $\beta\left(x_{n}, x\right) \geq 1$ for all $n \in \mathbb{N}$.

Then there exists $z \in X$ such that $z \in[S z]_{\alpha(z)} \cap[T z]_{\alpha(z)}$, that is, there exists a point $z \in X$ which is an $\alpha(z)$-fuzzy fixed point of $T$ and $S$.

Proof We will show that condition (23) implies condition (5) in Theorem 17. Suppose that $x, y \in X$ are such that

$$
\max \{\beta(x, y), \beta(y, x)\} \geq 1
$$

By using (23), we get

$$
\begin{aligned}
\tau & +H\left([S x]_{\alpha(x)},[T y]_{\alpha(y)}\right) \\
& \leq\left(\tau+H\left([S x]_{\alpha(x)},[T y]_{\alpha(y)}\right)\right)^{\max \{\beta(x, y), \beta(y, x)\}} \\
& \leq \tau+\phi\left(d(x, y), d\left(x,[S x]_{\alpha(x)}\right), d\left(y,[T y]_{\alpha(y)}\right), d\left(x,[T y]_{\alpha(y)}\right), d\left(y,[S x]_{\alpha(x)}\right)\right) .
\end{aligned}
$$


This implies that

$$
\begin{aligned}
& H\left([S x]_{\alpha(x)},[T y]_{\alpha(y)}\right) \\
& \quad \leq \phi\left(d(x, y), d\left(x,[S x]_{\alpha(x)}\right), d\left(y,[T y]_{\alpha(y)}\right), d\left(x,[T y]_{\alpha(y)}\right), d\left(y,[S x]_{\alpha(x)}\right)\right)
\end{aligned}
$$

Therefore, condition (5) in Theorem 17 holds. By Theorem 17, we get the desired result.

Corollary 24 Let $(X, d)$ be a complete metric space and let $S, T: X \rightarrow \mathcal{F}(X), \alpha: X \rightarrow(0,1]$ and $\beta: X \times X \rightarrow[0, \infty)$ be four mappings such that the following properties are fulfilled.

(a) For $x, y \in X$, we have $[S x]_{\alpha(x)},[T y]_{\alpha(y)} \in \mathrm{CB}(X)$.

(b) There exist $\phi \in \Phi$ and $\tau>1$ verifying

$$
\begin{aligned}
& (\tau-1+\max \{\beta(x, y), \beta(y, x)\})^{H\left([S x]_{\alpha(x)},[T y]_{\alpha(y)}\right)} \\
& \quad \leq \tau^{\phi\left(d(x, y), d\left(x,[S x]_{\alpha(x)}\right), d\left(y,[T y]_{\alpha(y)}\right), d\left(x,[T y]_{\alpha(y)}\right), d\left(y,[S x]_{\alpha(x)}\right)\right)}
\end{aligned}
$$

for all $x, y \in X$.

(c) $(S, T)$ is a $\beta_{\mathcal{F}}$-admissible pair.

(d) There exist $x_{0} \in X$ and $x_{1} \in\left[S x_{0}\right]_{\alpha\left(x_{0}\right)}$ such that $\beta\left(x_{0}, x_{1}\right) \geq 1$.

(e) At least one of the following properties holds.

(e.1) $T$ and $S$ are $\alpha$-continuous fuzzy mappings.

(e.2) If $x \in X$ and $\left\{x_{n}\right\}$ is a sequence in $X$ such that $\left\{x_{n}\right\} \rightarrow x$ and $\beta\left(x_{n}, x_{n+1}\right) \geq 1$ for all $n \in \mathbb{N}$, then $\beta\left(x_{n}, x\right) \geq 1$ for all $n \in \mathbb{N}$.

Then there exists $z \in X$ such that $z \in[S z]_{\alpha(z)} \cap[T z]_{\alpha(z)}$, that is, there exists a point $z \in X$ which is an $\alpha(z)$-fuzzy fixed point of $T$ and $S$.

Proof It is easy to see that condition (24) implies condition (5) in Theorem 17. Indeed, if $x, y \in X$ are such that

$$
\max \{\beta(x, y), \beta(y, x)\} \geq 1,
$$

by using (24), we have

$$
\begin{aligned}
\tau^{H\left([S x]_{\alpha(x),},[T y]_{\alpha(y)}\right)} & \leq(\tau-1+\max \{\beta(x, y), \beta(y, x)\})^{H\left([S x]_{\alpha(x)},[T y]_{\alpha(y)}\right)} \\
& \leq \tau^{\phi\left(d(x, y), d\left(x,[S x]_{\alpha(x)}\right), d\left(y,[T y]_{\alpha(y)}\right), d\left(x,[T y]_{\alpha(y)}\right), d\left(y,[S x]_{\alpha(x)}\right)\right)} .
\end{aligned}
$$

As the exponential function is strictly increasing when $\tau>1$, we get

$$
\begin{aligned}
& H\left([S x]_{\alpha(x)},[T y]_{\alpha(y)}\right) \\
& \quad \leq \phi\left(d(x, y), d\left(x,[S x]_{\alpha(x)}\right), d\left(y,[T y]_{\alpha(y)}\right), d\left(x,[T y]_{\alpha(y)}\right), d\left(y,[S x]_{\alpha(x)}\right)\right) .
\end{aligned}
$$

This shows that condition (5) in Theorem 17 holds. By Theorem 17, we get the desired result.

\section{Consequences}

In this section, we present some consequences of our main results applied to very different contexts: metric spaces endowed with arbitrary binary relations, metric spaces endowed with graphs. 


\section{1 $\alpha$-Fuzzy fixed point theorems on metric spaces endowed with arbitrary binary relations}

In this section, we present $\alpha$-fuzzy fixed point theorems on metric spaces endowed with arbitrary binary relations. The following notions and definitions are needed.

Let $(X, d)$ be a metric space and $\mathcal{R}$ be a binary relation over $X$. Let denote

$$
\mathcal{S}:=\mathcal{R} \cup \mathcal{R}^{-1},
$$

that is, $\mathcal{S}$ is the symmetric relation on $X$ such that, for all $x, y \in X$,

$$
x \mathcal{S} y \quad \Longleftrightarrow \quad x \mathcal{R} y \quad \text { or } y \mathcal{R} x \text {. }
$$

Next we introduce the notion of $\mathcal{R}_{\mathcal{F}}$-comparative pair of two fuzzy mappings.

Definition 25 Let $\mathcal{R}$ be a binary relation over metric space $(X, d)$ and let $\alpha: X \rightarrow(0,1]$ and $S, T: X \rightarrow \mathcal{F}(X)$ be three mappings. The ordered pair $(S, T)$ is said to be $\mathcal{R}_{\mathcal{F}}$-comparative if satisfies the following conditions:

(i) for each $x \in X$ and $y \in[S x]_{\alpha(x)}$ such that $x \mathcal{R} y$, we have $y \mathcal{R} z$ for all $z \in[T y]_{\alpha(y)}$;

(ii) for each $x \in X$ and $y \in[T x]_{\alpha(x)}$ such that $x \mathcal{R} y$, we have $y \mathcal{R} z$ for all $z \in[S y]_{\alpha(y)}$.

Here we show a $\alpha$-fuzzy fixed point theorem for $\mathcal{R}_{\mathcal{F}}$-comparative pair on metric spaces endowed with a binary relation.

Theorem 26 Let $(X, d)$ be a complete metric space, $\mathcal{R}$ be a binary relation over $X$ and let $S, T: X \rightarrow \mathcal{F}(X)$ and $\alpha: X \rightarrow(0,1]$ be three mappings such that the following properties are fulfilled.

(A) For $x, y \in X$, we have $[S x]_{\alpha(x)}$, $[T y]_{\alpha(y)} \in \mathrm{CB}(X)$.

(B) There exists $\phi \in \Phi$ verifying

$$
\begin{aligned}
& H\left([S x]_{\alpha(x)},[T y]_{\alpha(y)}\right) \\
& \quad \leq \phi\left(d(x, y), d\left(x,[S x]_{\alpha(x)}\right), d\left(y,[T y]_{\alpha(y)}\right), d\left(x,[T y]_{\alpha(y)}\right), d\left(y,[S x]_{\alpha(x)}\right)\right)
\end{aligned}
$$

for all $x, y \in X$ for which $x \mathcal{S} y$.

(C) $(S, T)$ is a $\mathcal{R}_{\mathcal{F}}$-comparative pair.

(D) There exist $x_{0} \in X$ and $x_{1} \in\left[S x_{0}\right]_{\alpha\left(x_{0}\right)}$ such that $x_{0} \mathcal{R} x_{1}$.

(E) At least one of the following properties holds.

(E.1) $T$ and $S$ are $\alpha$-continuous fuzzy mappings.

(E.2) If $x \in X$ and $\left\{x_{n}\right\}$ is a sequence in $X$ such that $\left\{x_{n}\right\} \rightarrow x$ and $x_{n} \mathcal{R} x_{n+1}$ for all $n \in \mathbb{N}$, then $x_{n} \mathcal{R} x$ for all $n \in \mathbb{N}$.

Then there exists $z \in X$ such that $z \in[S z]_{\alpha(z)} \cap[T z]_{\alpha(z)}$, that is, there exists a point $z \in X$ which is an $\alpha(z)$-fuzzy fixed point of $T$ and $S$.

Proof Consider the mapping $\beta: X \times X \rightarrow[0, \infty)$ defined by

$$
\beta(x, y)= \begin{cases}1, & \text { if } x \mathcal{R} y, \\ 0, & \text { otherwise }\end{cases}
$$


By using (25), for all $x, y \in X$, we get

$$
\begin{aligned}
\max \{\beta(x, y), \beta(y, x)\} \geq 1 & \\
\Rightarrow \quad(x \mathcal{R} y \text { or } y \mathcal{R} x) \Rightarrow & x \mathcal{S} y \\
\Rightarrow \quad H\left([S x]_{\alpha(x)},[T y]_{\alpha(y)}\right) \leq & \phi\left(d(x, y), d\left(x,[S x]_{\alpha(x)}\right), d\left(y,[T y]_{\alpha(y)}\right),\right. \\
& \left.d\left(x,[T y]_{\alpha(y)}\right), d\left(y,[S x]_{\alpha(x)}\right)\right) .
\end{aligned}
$$

This implies that condition (5) in Theorem 17 holds using mapping $\beta$. Since $(S, T)$ is a $\mathcal{R}_{\mathcal{F}^{-}}$ comparative pair, it is also a $\beta_{\mathcal{F}}$-admissible pair. From (D) and definition of $\beta$, we find that there exist $x_{0} \in X$ and $x_{1} \in\left[S x_{0}\right]_{\alpha\left(x_{0}\right)}$ such that $\beta\left(x_{0}, x_{1}\right) \geq 1$. Furthermore, it is easy to see that condition (E.2) implies condition (e.2). Therefore, all hypotheses of Theorem 17 are satisfied. As a consequence, we can find a point $z \in X$ which is an $\alpha(z)$-fuzzy fixed point of $T$ and $S$. This completes the proof.

\section{2 $\alpha$-Fuzzy fixed point theorems on metric spaces endowed with graph}

In this section, we study existence of $\alpha$-fuzzy fixed points on a metric space endowed with graph. To do that, let $(X, d)$ be a metric space. The subset $\{(x, x): x \in X\}$ is called the diagonal of the Cartesian product $X \times X$ and it is denoted by $\Delta$. Consider a graph $G$ such that the set $V(G)$ of its vertices coincides with $X$ and the set $E(G)$ of its edges contains all loops, i.e., $\Delta \subseteq E(G)$. We assume $G$ has no parallel edges, so we can identify $G$ with the pair $(V(G), E(G))$. Moreover, we may treat $G$ as a weighted graph by assigning to each edge the distance between its vertices.

Next we introduce the notion of $G_{\mathcal{F}}$-edge pair of fuzzy mappings.

Definition 27 Let $(X, d)$ be a metric space endowed with a graph $G$ and let $\alpha: X \rightarrow(0,1]$ and $S, T: X \rightarrow \mathcal{F}(X)$ be three mappings. The ordered pair $(S, T)$ is said to be $G_{\mathcal{F}}$-edge if it satisfies the following conditions:

(i) for each $x \in X$ and $y \in[S x]_{\alpha(x)}$, with $(x, y) \in E(G)$, we have $(y, z) \in E(G)$ for all $z \in[T y]_{\alpha(y)}$

(ii) for each $x \in X$ and $y \in[T x]_{\alpha(x)}$, with $(x, y) \in E(G)$, we have $(y, z) \in E(G)$ for all $z \in[S y]_{\alpha(y)}$.

Now we state and prove an $\alpha$-fuzzy fixed point theorem for $G_{\mathcal{F}}$-edge pairs on metric spaces endowed with graphs.

Theorem 28 Let $(X, d)$ be a complete metric space endowed with a graph $G$ and let $S, T$ : $X \rightarrow \mathcal{F}(X)$ and $\alpha: X \rightarrow(0,1]$ be three mappings such that the following properties are fulfilled.

(A) For $x, y \in X$, we have $[S x]_{\alpha(x)}$, $[T y]_{\alpha(y)} \in \mathrm{CB}(X)$.

(B) There exists $\phi \in \Phi$ verifying

$$
\begin{aligned}
& H\left([S x]_{\alpha(x)},[T y]_{\alpha(y)}\right) \\
& \quad \leq \phi\left(d(x, y), d\left(x,[S x]_{\alpha(x)}\right), d\left(y,[T y]_{\alpha(y)}\right), d\left(x,[T y]_{\alpha(y)}\right), d\left(y,[S x]_{\alpha(x)}\right)\right)
\end{aligned}
$$

for all $x, y \in X$ for which $(x, y) \in E(G)$. 
(C) $(S, T)$ is a $G_{\mathcal{F}}$-edge pair.

(D) There exist $x_{0} \in X$ and $x_{1} \in\left[S x_{0}\right]_{\alpha\left(x_{0}\right)}$ such that $\left(x_{0}, x_{1}\right) \in E(G)$.

(E) At least one of the following properties holds.

(E.1) $T$ and $S$ are $\alpha$-continuous fuzzy mappings.

(E.2) If $x \in X$ and $\left\{x_{n}\right\}$ is a sequence in $X$ such that $\left\{x_{n}\right\} \rightarrow x$ and $\left(x_{n}, x_{n+1}\right) \in E(G)$ for all $n \in \mathbb{N}$, then $\left(x_{n}, x\right) \in E(G)$ for all $n \in \mathbb{N}$.

Then there exists $z \in X$ such that $z \in[S z]_{\alpha(z)} \cap[T z]_{\alpha(z)}$, that is, there exists a point $z \in X$ which is an $\alpha(z)$-fuzzy fixed point of $T$ and $S$.

Proof This proof is similar to the proof of Theorem 26 by considering the mapping $\beta$ : $X \times X \rightarrow[0, \infty)$ defined by

$$
\beta(x, y)= \begin{cases}1, & \text { if }(x, y) \in E(G) \\ 0, & \text { otherwise }\end{cases}
$$

\section{Application to a common fixed point for multi-valued mappings}

In this section, we study some relationships between multi-valued mappings and fuzzy mappings. Here, using the concept of $\beta$-admissible pair of multi-valued mappings due to Phiangsungnoen et al. [11] (recall Definition 12), we indicate that Theorem 17 can also be employed to derive some common fixed point results for multi-valued mapping.

Theorem 29 Let $(X, d)$ be a complete metric space and let $F, G: X \rightarrow \mathrm{CB}(X)$ and $\beta: X \times$ $X \rightarrow[0, \infty)$ be three mappings such that the following properties are fulfilled.

$\left(\star_{1}\right)$ There exists $\phi \in \Phi$ verifying for $x, y \in X$,

$$
\begin{aligned}
& \max \{\beta(x, y), \beta(y, x)\} \geq 1 \\
& \Rightarrow \quad H(F x, G y) \leq \phi(d(x, y), d(x, F x), d(y, G y), d(x, G y), d(y, F x)) .
\end{aligned}
$$

$\left(\star_{2}\right)(F, G)$ is a $\beta$-admissible pair.

$\left(\star_{3}\right)$ There exist $x_{0} \in X$ and $x_{1} \in F x_{0}$ such that $\beta\left(x_{0}, x_{1}\right) \geq 1$.

$\left(\star_{4}\right)$ At least one of the following properties holds.

$\left(\star_{4,1}\right) F$ and $G$ are continuous mappings.

$\left(\star_{4,2}\right)$ If $x \in X$ and $\left\{x_{n}\right\}$ is a sequence in $X$ such that $\left\{x_{n}\right\} \rightarrow x$ and $\beta\left(x_{n}, x_{n+1}\right) \geq 1$ for all $n \in \mathbb{N}$, then $\beta\left(x_{n}, x\right) \geq 1$ for all $n \in \mathbb{N}$.

Then there exists $u \in X$ such that $u \in F u \cap G u$, that is, $F$ and $G$ have a common fixed point.

Proof Let $\alpha: X \rightarrow(0,1]$ be an arbitrary mapping. Consider two fuzzy mappings $S, T: X \rightarrow$ $\mathcal{F}(X)$ defined by

$$
(S x)(t)= \begin{cases}\alpha(x), & \text { if } t \in F x, \\ 0, & \text { if } t \notin F x\end{cases}
$$

and

$$
(T x)(t)= \begin{cases}\alpha(x), & \text { if } t \in G x, \\ 0, & \text { if } t \notin G x .\end{cases}
$$


By definition of $S$ and $T$, we get

$$
[S x]_{\alpha(x)}=\{t: S x(t) \geq \alpha(x)\}=F x
$$

and

$$
[T x]_{\alpha(x)}=\{t: T x(t) \geq \alpha(x)\}=G x .
$$

Hence condition (27) turns into condition (5) in Theorem 17. Also, we find that the other conditions in Theorem 17 hold. Therefore, Theorem 17 can be applied to obtain $u \in X$ such that

$$
u \in[S u]_{\alpha(u)} \cap[T u]_{\alpha(u)}=F u \cap G u,
$$

that is, $u$ is a common fixed point of $F$ and $G$. This completes the proof.

Remark 30 Theorem 29 improves Theorem 4.3 of Phiangsungnoen et al. [11]. Also, Theorem 29 extends and generalizes Corollary 7 of Azam and Beg in [7]. Moreover, Theorem 29 is a complementary result of the famous Nadler contraction mapping principle [3].

By using Corollaries 20,23, and 24, we get the following results.

Corollary 31 Let $(X, d)$ be a complete metric space and let $F, G: X \rightarrow \mathrm{CB}(X)$ and $\beta: X \times$ $X \rightarrow[0, \infty)$ be three mappings such that the following properties are fulfilled.

$\left(\star_{1}\right)$ There exists $\phi \in \Phi$ verifying

$$
\max \{\beta(x, y), \beta(y, x)\} H(F x, G y) \leq \phi(d(x, y), d(x, F x), d(y, G y), d(x, G y), d(y, F x))
$$

for all $x, y \in X$.

$\left(\star_{2}\right)(F, G)$ is a $\beta$-admissible pair.

$\left(\star_{3}\right)$ There exist $x_{0} \in X$ and $x_{1} \in F x_{0}$ such that $\beta\left(x_{0}, x_{1}\right) \geq 1$.

$\left(\star_{4}\right)$ At least one of the following properties holds.

$\left(\star_{4,1}\right) F$ and $G$ are continuous mappings.

$\left(\star_{4.2}\right)$ If $x \in X$ and $\left\{x_{n}\right\}$ is a sequence in $X$ such that $\left\{x_{n}\right\} \rightarrow x$ and $\beta\left(x_{n}, x_{n+1}\right) \geq 1$ for all $n \in \mathbb{N}$, then $\beta\left(x_{n}, x\right) \geq 1$ for all $n \in \mathbb{N}$.

Then there exists $u \in X$ such that $u \in F u \cap G u$, that is, $F$ and $G$ have a common fixed point.

Corollary 32 Let $(X, d)$ be a complete metric space and let $F, G: X \rightarrow \mathrm{CB}(X)$ and $\beta: X \times$ $X \rightarrow[0, \infty)$ be three mappings such that the following properties are fulfilled.

$\left(\star_{1}\right)$ There exist $\phi \in \Phi$ and $\tau \geq 1$ verifying

$$
(\tau+H(F x, G y))^{\max \{\beta(x, y), \beta(y, x)\}} \leq \tau+\phi(d(x, y), d(x, F x), d(y, G y), d(x, G y), d(y, F x))
$$

for all $x, y \in X$. 
$\left(\star_{2}\right)(F, G)$ is a $\beta$-admissible pair.

$\left(\star_{3}\right)$ There exist $x_{0} \in X$ and $x_{1} \in F x_{0}$ such that $\beta\left(x_{0}, x_{1}\right) \geq 1$.

$\left(\star_{4}\right)$ At least one of the following properties holds.

$\left(\star_{4.1}\right) F$ and $G$ are continuous mappings.

$\left(\star_{4.2}\right)$ If $x \in X$ and $\left\{x_{n}\right\}$ is a sequence in $X$ such that $\left\{x_{n}\right\} \rightarrow x$ and $\beta\left(x_{n}, x_{n+1}\right) \geq 1$ for all $n \in \mathbb{N}$, then $\beta\left(x_{n}, x\right) \geq 1$ for all $n \in \mathbb{N}$.

Then there exists $u \in X$ such that $u \in F u \cap G u$, that is, $F$ and $G$ have a common fixed point.

Corollary 33 Let $(X, d)$ be a complete metric space and let $F, G: X \rightarrow \mathrm{CB}(X)$ and $\beta: X \times$ $X \rightarrow[0, \infty)$ be three mappings such that the following properties are fulfilled.

$\left(\star_{1}\right)$ There exist $\tau \geq 1$ and $\phi \in \Phi$ verifying

$$
(\tau-1+\max \{\beta(x, y), \beta(y, x)\})^{H(F x, G y)} \leq \tau^{\phi(d(x, y), d(x, F x), d(y, G y), d(x, G y), d(y, F x))}
$$

for all $x, y \in X$.

$\left(\star_{2}\right)(F, G)$ is a $\beta$-admissible pair.

$\left(\star_{3}\right)$ There exist $x_{0} \in X$ and $x_{1} \in F x_{0}$ such that $\beta\left(x_{0}, x_{1}\right) \geq 1$.

$\left(\star_{4}\right)$ At least one of the following properties holds.

$\left(\star_{4.1}\right) F$ and $G$ are continuous mappings.

$\left(\star_{4.2}\right)$ If $x \in X$ and $\left\{x_{n}\right\}$ is a sequence in $X$ such that $\left\{x_{n}\right\} \rightarrow x$ and $\beta\left(x_{n}, x_{n+1}\right) \geq 1$ for all $n \in \mathbb{N}$, then $\beta\left(x_{n}, x\right) \geq 1$ for all $n \in \mathbb{N}$.

Then there exists $u \in X$ such that $u \in F u \cap G u$, that is, $F$ and $G$ have a common fixed point.

\section{Competing interests}

The authors declare that they have no competing interests.

\section{Authors' contributions}

All authors contributed equally and significantly in writing this article. All authors read and approved the final manuscript.

\section{Author details}

${ }^{1}$ Department of Mathematics, King Abdulaziz University, P.O. Box 80203, Jeddah, 21589, Saudi Arabia. ${ }^{2}$ Department of Mathematics, University of Jaén, Campus las Lagunillas s/n, Jaén, 23071, Spain. ${ }^{3}$ Department of Mathematics and Statistics, Faculty of Science and Technology, Thammasat University, Rangsit Center, Pathumthani, 12121, Thailand.

\section{Acknowledgements}

The authors thank the referees and the editor for their insightful comments that helped to improve this manuscript. The first author gratefully acknowledges the support from the Deanship of Scientific Research (DSR) at King Abdulaziz University (KAU) during this research.

Received: 5 July 2014 Accepted: 11 November 2014 Published: 28 Nov 2014

\footnotetext{
References

1. Zadeh, LA: Fuzzy sets. Inf. Control 8, 103-112 (1965)

2. Heilpern, S: Fuzzy mappings and fixed point theorems. J. Math. Anal. Appl. 83, 566-569 (1981)

3. Nadler, SB Jr.: Multivalued contraction mapping. Pac. J. Math. 30(2), 475-488 (1969)

4. Frigon, M, O'Regan, D: Fuzzy contractive maps and fuzzy fixed points. Fuzzy Sets Syst. 129, $39-45$ (2002)

5. Azam, A, Beg, I: Common fixed points of fuzzy maps. Math. Comput. Model. 49, 1331-1336 (2009)

6. Azam, A, Arshad, M, Beg, I: Fixed points of fuzzy contractive and fuzzy locally contractive maps. Chaos Solitons Fractals 42, 2836-2841 (2009)

7. Azam, A, Beg, I: Common fuzzy fixed points for fuzzy mappings. Fixed Point Theory Appl. 2013, 14 (2013)
} 
8. Azam, A, Arshad, M: A note on 'Fixed point theorems for fuzzy mappings' by P. Vijayaraju and M. Marudai. Fuzzy Sets Syst. 161, 1145-1149 (2010)

9. Bose, RK, Sahani, D: Fuzzy mappings and fixed point theorems. Fuzzy Sets Syst. 21, 53-58 (1987)

10. Vijayaraju, P, Marudai, M: Fixed point theorems for fuzzy mappings. Fuzzy Sets Syst. 135, 401-408 (2003)

11. Phiangsungnoen, $S$, Sintunavarat, W, Kumam, P: Common $\alpha$-fuzzy fixed point theorems for fuzzy mappings via $\beta_{\mathcal{F}}$-admissible pair. J. Intell. Fuzzy Syst. 27(5), 2463-2472 (2014)

12. Mohammadi, B, Rezapour, S, Shahzad, N: Some results on fixed points of $\alpha$ - $\psi$-Ciric generalized multifunctions. Fixed Point Theory Appl. 2013, 24 (2013)

13. Pedraza, T, Rodríguez-López, J, Romaguera, S: Convergence of fuzzy sets with respect to the supremum metric. Fuzzy Sets Syst. 245, 83-100 (2014)

14. Qiu, D, Lu, C, Zhang, W, Mo, Y: On common fixed point theorems in the stationary fuzzy metric space of the bounded closed sets. Abstr. Appl. Anal. 2013, Article ID 951259 (2013)

15. Qiu, D, Shu, L: Supremum metric on the space of fuzzy sets and common fixed point theorems for fuzzy mappings. Inf. Sci. 178, 3595-3604 (2008)

16. Qiu, D, Shu, L, Guan, J: Common fixed point theorems for fuzzy mappings under $\Phi$-contraction condition. Chaos Solitons Fractals 41, 360-367 (2009)

17. Roldán-López-de-Hierro, AF, Martínez-Moreno, J, Roldán-López-de-Hierro, C, Cho, YJ: Multidimensional coincidence point results for compatible mappings in partially ordered fuzzy metric spaces. Fuzzy Sets Syst. 251, 71-82 (2014)

18. Roldán, A, Martínez-Moreno, J, Roldán, C: Tripled fixed point theorem in fuzzy metric spaces and applications. Fixed Point Theory Appl. 2013, 29 (2013)

19. Samet, B, Vetro, C, Vetro, P: Fixed point theorems for $\alpha$ - $\psi$-contractive type mappings. Nonlinear Anal. 75, 2154-2165 (2012)

20. Karapınar, E, Samet, B: Generalized $\alpha-\psi$ contractive type mappings and related fixed point theorems with applications. Abstr. Appl. Anal. 2012, Article ID 793486 (2012)

21. Roldán-López-de-Hierro, AF, Karapınar, E, Manro, S: Some new fixed point theorems in fuzzy metric spaces. J. Intell. Fuzzy Syst. 27, 2257-2264 (2014)

22. Berzig, M, Karapınar, E, Roldán-López-de-Hierro, AF: Discussion on generalized- $(\alpha \psi, \beta \varphi)$-contractive mappings via generalized altering distance function and related fixed point theorems. Abstr. Appl. Anal. 2013, Article ID 259768 (2013)

23. Karapınar, E: $\alpha-\psi$-Geraghty contraction type mappings and some related fixed point results. Filomat 28(1), 37-48 (2014)

24. Berzig, M, Karapınar, E: Note on 'Modified $\alpha$ - $\psi$-contractive mappings with application'. Thai J. Math. (in press)

25. Berzig, $\mathrm{M}$, Karapınar, E: Fixed point results for $(\alpha \psi, \beta \varphi)$-contractive mappings for a generalized altering distance. Fixed Point Theory Appl. 2013, 205 (2013)

26. Karapınar, E, Sintunavarat, W: An optimal approximate solution theorems for $\alpha$-proximal contraction non-self mappings and applications. Fixed Point Theory Appl. 2013, 323 (2013)

27. Roldán-López-de-Hierro, AF, Martínez-Moreno, J, Roldán-López-de-Hierro, C: On interrelationships between fuzzy metric structures. Iran. J. Fuzzy Syst. 10(2), 133-150 (2013)

28. Bae, J-S, Cho, S-H, Karapınar, E: Fixed point theorems for $\alpha$-Geraghty contraction type maps in metric spaces. Fixed Point Theory Appl. 2013, 329 (2013)

29. Cho, YJ, Martínez-Moreno, J, Roldán-López-de-Hierro, AF, Roldán-López-de-Hierro, C: Coupled coincidence point theorems in (intuitionistic) fuzzy normed spaces. J. Inequal. Appl. 2013, 104 (2013)

30. Karapınar, E, Shahi, P, Tas, K: Generalized $\alpha-\psi$-contractive type mappings of integral type and related fixed point theorems. J. Inequal. Appl. 2014, 160 (2014)

31. Kumam, P, Martínez-Moreno, J, Roldán-López-de-Hierro, AF, Roldán-López-de-Hierro, C: Berinde-Borcut tripled fixed point theorem in partially ordered (intuitionistic) fuzzy normed spaces. J. Inequal. Appl. 2014, 47 (2014)

32. Asl, JH, Rezapour, S, Shahzad, N: On fixed points of $\alpha$ - $\psi$-contractive multifunctions. Fixed Point Theory Appl. 2012, $212(2012)$

10.1186/1687-1812-2014-234

Cite this article as: Latif et al.: On common $\alpha$-fuzzy fixed points with applications. Fixed Point Theory and Applications 2014, 2014:234

\section{Submit your manuscript to a SpringerOpen ${ }^{\circ}$ journal and benefit from:}

- Convenient online submission

- Rigorous peer review

- Immediate publication on acceptance

- Open access: articles freely available online

- High visibility within the field

- Retaining the copyright to your article

Submit your next manuscript at $>$ springeropen.com 